\title{
Set-Based Concurrent Engineering Process Model and Systematic Application on an Electronic Card Reader
}

\author{
AHMED AL-ASHAAB ${ }^{\mathrm{a}}$, ZEHRA CANAN ARACI $^{\mathrm{b}}$, MUHD IKMAL I. MOHD MAULANA ${ }^{\mathrm{a}}$, CESAR \\ GARCIA ALMEIDA ${ }^{\mathrm{a}}$ AND STEVE YOUNG ${ }^{\mathrm{a}}$. \\ a Department of Manufacturing \\ Cranfield University \\ College Road, Bedford, MK43 0AH \\ UNITED KINGDOM
}

$\mathrm{b}$ Department of Industrial Engineering and Engineering Management

University of Sharjah

27272, Sharjah

UNITED ARAB EMIRATES

\begin{abstract}
Set-based concurrent engineering (SBCE), also known as set-based design, is a state-of-the-art approach to the new product development process. SBCE, simply, provides an environment where designers explore a wide range of alternative solutions in the early stages of product development. After gaining knowledge, solutions are narrowed down until the optimal solution is ensured. Such an environment saves considerable amount of cost and time while reaching innovation and high quality in the products. However, industrial practitioners seek a clear and systematic application throughout an SBCE process. This paper demonstrates a well-structured SBCE process model and its step-by-step application on a product called "electronic card reader". Real data is used in the industrial case study. Results showed the benefits of applying SBCE in both the product, and the process of new product development.
\end{abstract}

Key words: - New product development; Lean product development; lean thinking; Set-Based Concurrent Engineering; Knowledge Reuse; Innovation.

Received: May 28, 2021. Revised: October 15, 2021. Accepted: October 30, 2021. Published: November 23, 2021.

\section{Introduction}

Product development plays a vital role in an organization's growth and success in terms of competitiveness, business profitability, introduction of a variety of models, and most importantly reducing the manufacturing costs. The demand for a quality, reliable product at an affordable price has put pressure on manufacturing companies to make a product that meets these criteria. It is impossible to make an efficient transformation in product development without considering the current product development challenges [1], [13], [15]. [30] comprehensively reviewed the challenges: rework in the design due to last minute changes from customers, lack of knowledge, lack of innovation, to name but a few. design space in the early stages of product development. Depending on the complexity of the product the use of resources increases accordingly. Set-based concurrent engineering (SBCE) inherents the fact of reusing the product-knowledge from previous projects/experiences such as PLMs, databases, research and development, even failed projects. Rather than designing from scratch, SBCE retrieves all the possible design options of the systems or subsystems of the product in the very beginning of the new product development project. In other words, SBCE reuses the knowledge that exists in the organization.

[58] proposed the principles of SBCE technique. However, there is a lack of a clear structured SBCE process model [56], lack of clear guidelines on how to implement the SBCE 
in practice [3], [11], and limited numbers of case studies in the industry [62]. Therefore, this paper clarifies a well-structured SBCE process model while demonstrating the potential benefits in a real industrial case study.

This paper is structured as follows: First of all, authors, comprehensively, reviewed the literature portraying the set-based concurrent engineering from its principles to the current practices (Section 2). Following the literature review, the SBCE process model has been demonstrated (Section 3). Step-by-step implementation of this process model is validated by an industrial case study of an electronic card reader which is a part of proximity access system (Section 4). Results of the case study have been discussed (Section 5) and then conclusions have been formulated (Section 6).

\section{An Overview of Set-Based Concurrent Engineering}

\subsection{SBCE within Lean Product Development}

The literature emphasises on the importance of set-based concurrent engineering (SBCE) within the lean product development (LeanPD) application [28], [30], [42], [62], [58]. This is because SBCE represents the definition of the process that will be followed to develop a product. It focuses on value creation, provision of a "knowledge environment", continuous improvement and SBCE process that encourage innovation and collaboration. LeanPD provides a process model and associated tools that consider the entire product life cycle. It provides knowledge-based user-centric design and a development environment to support value creation to the customers in terms of innovation and customisation, and quality as well as sustainable and affordable products. Therefore, a good LeanPD should address the following; 1) Clear lean principles, 2) Well-defined elements where at least one of them describes a development process, 3) Description of the tools and methods, 4) Implementation guidelines, and finally, 5) Case studies to demonstrate the approach.

In the few recent decades, scholars and practitioners have been studying on the development of a certain model or framework. [42] presented a detailed description of the 13 principles that shaped the "Toyota lean product development system" model that consists of subsystems; process, people, tools, and technology. They stated clearly that the model does not explain the way that lean product development works in reality. A case study has been conducted at Ford Body and Stamping Engineering [36] where the first step was to get the people, culture, and organization right with an "attitude change" and a serious "focus on customer" mentality. Similarly, the 13 principles were addressed. This helped to perform several tasks simultaneously for longer periods and delay key decisions until later in the process which help to achieve a good level of SBCE application.

[27] and [28] are two books which can be considered as "business novel". While mechanisms of LeanPD are uniquely described, methods and tools provided limited guidance. On the other hand, [47] described several companies' experiences achieving a significant result by emphasising the method and implementation of the LeanPD, however, the SBCE process has not been described in detail.

Several studies developed a different LeanPD framework [5], [23], [34], [44], [65]. All the developed frameworks have been graphically represented in the form of tables based on the review of other LeanPD and product development literature. The researchers of these LeanPD frameworks have appreciated the foundation of LeanPD to be the Toyota product development system (TPDS). They incorporated some elements of TPDS into the five lean principles from [68] which are combined with ideas from traditional product development to formulate their frameworks. Nevertheless, limited applications of SBCE are documented in detail [21], [62].

LeanPD theory and application should be considered as a holistic approach rather than developing or implementing individual elements of LeanPD [2]. This holistic approach should focus on value creation, knowledge environment, continuous improvement, and processes that encourage innovation and collaboration. All these elements can be provided by SBCE which is the core enabler of 
LeanPD. The following sub-section presents the evolving concept of SBCE.

\subsection{Applications and Practices of SBCE}

[66] discovered that the real success of Japanese manufacturers originated from the Toyota Product Development System (TPDS) rather than their production system. [58] describes SBCE as a process of reasoning, developing, and communicating a set of solutions in parallel. As the design progresses, the set is gradually narrowed down the gained knowledge. [42] stressed that SBCE, thoroughly, explores alternative solutions until there is maximum "design space".

[20] developed a system dynamics model to simulate a product development process in which four alternative automobile systems (e.g. cooling) are simultaneously designed. If future conditions are uncertain and changing the strategy later incurs substantial costs, then having flexible strategies and delaying decisions can increase project value when compared to making all key strategic decisions early in the project. [29] has proposed SBCE Innovation Roadmap to simplify the implementation. However, their work did not show an SBCE process model or a reference to use an existing one. The overall idea is to use commonly wellknown tools; QFD and TRIZ in order to integrate customer requirements into a technical quality characteristics and support search efforts to find innovative solutions. Another study has been conducted to help to drive SBCE through engineering relationship which incorporate fuzzy set theory/logic and the automated analysis of design parameters by means of mathematical algorithms [9], [24], [41], [43], [46], [59], [61]. However, the studies focused about the decisions under uncertainty, design optimisation and incorporating designer preferences without showing a detail application of the SBCE process model.

[14] developed a software model to optimise SBCE communication and knowledge sharing. The software tools present the main information about communication mechanisms with relation to SBCE baseline model from [32]. [35] outlined SBCE with the software application providing designers a tool to re-use design knowledge of the products by utilising a function-means modelling and trade-off curves. Trade-off curves have been implemented to demonstrate SBCE activities such as creating a set of design solutions [7], communicating and narrowing down the design set [6] and creating a knowledge environment [8]. In addition to these studies, [21] also propose a method that would explore the design space of an SBCE application (e.g. ADOPT stands for Augmented set-based Design and OPTimisation). This method supports SBCE to identify the optimum configurations and to tradeoff for further evaluation and assessment. [18] used SBCE as a research methodology for wearable metaproducts in order to test alternative designs during the product development phase. The benefit of such a practice was to explore designsets in parallel and choose the suitable components for prototyping. These studies are to ensure feasibility in the entire design space before committing to a design by validating it in two levels; 1) design spaces created within each system, and 2) discrete design spaces resulting from a combination of several systems. Although, all the mentioned researches clearly contributed to the application of SBCE, a systematic implementation has not been provided through a process model.

[66] provided a case study to support an evidence that SBCE is the cause of Toyota's various success. However the case study does not present a detail process or methodology to perform the SBCE. [38] developed, what they refer to as, a set-based approach to multi-scale design by means of modelling and simulation at Schlumberger with the benefits of greater solution variety and a lower risk of not finding any feasible solution and having to go through expensive iterations. [49] conducted a number of case studies on mechanical engineering products to test principles of SBCE, based on the work of [58] with improvements in product cost and performance, level of innovation, project risk, and a reduction in engineering changes. [2] performed a case study on the SBCE model at an aerospace company for the transformation into lean environment. This transformation was achieved in two main stages: 1) Integrating the principles of SBCE into an existing product development model, and 2) Implementation of the developed model in a research-based 
industrial case study of a helicopter engine. The case study deliberates on how a company can integrate the principles of SBCE within its own product development process and evaluated its benefits.
Throughout the recent years, the interest in the SBCE applications has increased. There have been several studies conducted related to the implementation of SBCE in a real industrial setting. These researches have been categorized and displayed in Table 2.

\begin{tabular}{|c|c|c|c|c|c|}
\hline Category & $\begin{array}{l}1 \\
\text { Industrial } \\
\text { case study }\end{array}$ & $\begin{array}{l}2 \\
\text { Design set }\end{array}$ & $\begin{array}{l}3 \\
\text { Supporting } \\
\text { SBCE }\end{array}$ & $\begin{array}{l}4 \\
\text { SBCE as } \\
\text { methodology }\end{array}$ & $\begin{array}{l}5 \\
\text { Reference } \\
\text { to SBCE }\end{array}$ \\
\hline [11] & $\mathrm{x}$ & & & & \\
\hline [12] & $\mathrm{X}$ & & & $\mathrm{X}$ & \\
\hline [17] & & & & & $\mathrm{x}$ \\
\hline [26] & $\mathrm{X}$ & & & & $\mathrm{x}$ \\
\hline [55] & & & & & $\mathrm{x}$ \\
\hline [57] & & $\mathrm{X}$ & $\mathrm{X}$ & & \\
\hline [60] & & & $\mathrm{x}$ & & \\
\hline [63] & & & & & $\mathrm{x}$ \\
\hline [4] & $\mathrm{X}$ & $\mathrm{X}$ & & $\mathrm{X}$ & \\
\hline [19] & & & $\mathrm{x}$ & $\mathrm{X}$ & $\mathrm{x}$ \\
\hline [25] & $\mathrm{X}$ & & & $\mathrm{X}$ & \\
\hline [37] & & & & $\mathrm{x}$ & \\
\hline [16] & & & & $\mathrm{X}$ & \\
\hline [53] & $\mathrm{X}$ & & & & \\
\hline [50] & & & $\mathrm{x}$ & & $\mathrm{X}$ \\
\hline [52] & $\mathrm{X}$ & & & & $\mathrm{x}$ \\
\hline [64] & & $\mathrm{x}$ & & $\mathrm{x}$ & \\
\hline [69] & & & $\mathrm{x}$ & & \\
\hline [48] & & & $\mathrm{x}$ & & \\
\hline [51] & $\mathrm{x}$ & & & $\mathrm{x}$ & \\
\hline$[33]$ & $\mathrm{X}$ & $\mathrm{X}$ & & $\mathrm{X}$ & \\
\hline [40] & & & $\mathrm{X}$ & & \\
\hline
\end{tabular}

Table 2. SBCE Applications and Practices between the Years 2016 and 2020

The meaning of each category is clarified as follows:

1. Industrial case study: Papers in this category implement set-based concurrent engineering principles in an industrial case study. However, these studies do not demonstrate a clear process model/framework of SBCE.

2. Design set: Set-based concurrent engineering is implemented to explore a set of design solutions.

3. Supporting SBCE: Papers in this category do not implement SBCE directly but propose tools and methods to support SBCE applications (e.g. creating knowledge while exploring the design space[60]).

4. SBCE as methodology: Set-based concurrent engineering is not implemented alone but as a supportive approach to product development. Papers in this category utilize other product development tools/approaches together with SBCE (e.g. multidisciplinary robust design optimization (MRDO) [69]).

5. Reference to SBCE: Set-based concurrent engineering is not 
implemented, however, recommended by the authors as an effective product development approach (e.g. the collaborator company desires to use SBCE approach [17]).

Findings of the literature review show that there have been several attempts to utilize SBCE, but, based on its principles. Practitioners seek a clear pathway to implement set-based concurrent engineering, however, it is challenging to find one well-structured process model which guides companies step-by-step in the early stages of product development. This paper demonstrates both a systematic SBCE process model and its implementation in an industrial case study.

\section{The SBCE process model}

The principles of SBCE have been identified in several literature and classified into five categories which are 1) map the design space, 2) integrate by intersection, 3) establish feasibility before commitment, 4) strategic value research and alignment, and 5) create and explore multiple concepts in parallel [32], [42], [58], [66], [67]. These principles have been explored thoroughly and aggregated by [30] as illustrated in Table 1.

Based on the SBCE principles (Table 1), the SBCE baseline model has been developed as illustrated in Figure 1 [32]. Furthermore, it delineated that the customer and supplier are involved from start to finish in the process of

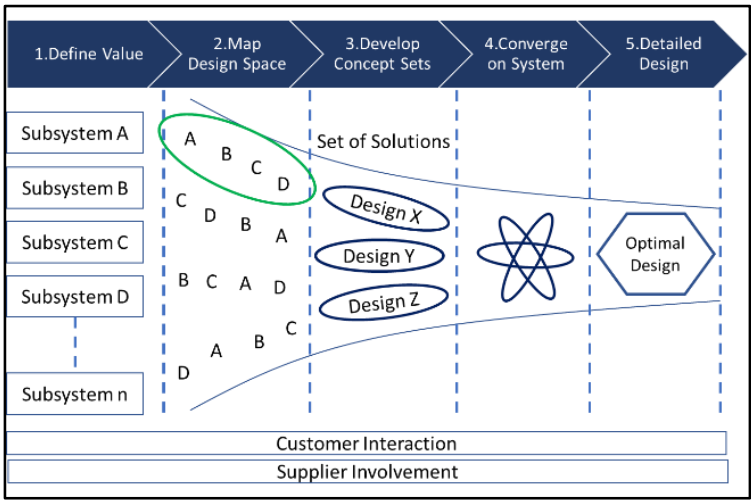

product development to establish robust and efficient communications. It also empowers the suppliers to develop their own

SBCE which benefited to reduce supplier tracking and enhance the innovation.

Figure 1. The SBCE baseline model (adapted from [32])

The most important area of SBCE process is the creation and exploration of solution sets which [66] provided with limited methodological guidance. Therefore, there was an urge to develop a step-by-step guidance which was in the form of SBCE process model. Creation and exploration of solution-sets have been indicated as a category and important additions have been incorporated to guide the process [2], [31], [39]. Each category-list in Table 1 has been represented as a key stage of the SBCE baseline model, namely; 1) Define value, 2) Map Design space, 3) Develop concept sets, 4) Converge on system and 5) Detailed design. In addition, most of the SBCE principles listed in Table 1 have been translated into activities to form the SBCE process model as shown in Figure 2. In Table 1, the principle 1.a. "Explores customer value for project X" has been translated as activity 1.1 "Classify project type" in Figure 2. Similarly, the principle 1.c. "aligns each project with the company value strategy" has been translated into activity 1.2 "Explore customer value". The same approach is followed in the rest of the SBCE activities in Figure 2. This SBCE process model has been developed as part of the LeanPPD project with consultation and inputs from the industrial partners namely: Rolls-Royce, Volkswagen, Visteon, Sitech, and Indesit. 
WSEAS TRANSACTIONS ON COMPUTERS

DOI: 10.37394/23205.2021.20.36
Ahmed Al-Ashaab, Zehra Canan Araci, Muhd Ikmal I. Mohd Maulana, Cesar Garcia Almeida, Steve Young

\begin{tabular}{|c|c|}
\hline Category & Principle \\
\hline $\begin{array}{l}\text { 1. Strategic value } \\
\text { research and alignment }\end{array}$ & \begin{tabular}{|ll} 
a. & Classify projects into a project portfolio (Morgan and Liker, 2006; Ward, 2007) \\
b. & Explore customer value for project X (Morgan and Liker,2006; Ward, 2007) \\
c. & Align each project with the company value strategy (Ward, 2007) \\
d. & Translate customer value (product vision) to designers (via concept paper) (Sobek et al.., 1999; \\
Morgan and Liker, 2006)
\end{tabular} \\
\hline 2. Map the design Space & $\begin{array}{ll}\text { a. } & \text { Break the system down into subsystems (Ward, 2007) } \\
\text { b. Identify essential characteristics for the system (Ward, 2007) } \\
\text { c. Decide on what subsystems/components improvements should be made and to what level } \\
\text { (selective innovation) (Ward, 2007) } \\
\text { d. Define feasible regions based on knowledge, past experience and the Chief engineer, and } \\
\text { consider the different perspectives/functional groups (Sobek et al., 1999) }\end{array}$ \\
\hline $\begin{array}{l}\text { 3. Create and Explore } \\
\text { multiple concepts in } \\
\text { parallel }\end{array}$ & $\begin{array}{ll}\text { a. } & \text { Pull innovative concepts from R\&D departments (Ward, 2007) } \\
\text { b. } & \text { Explore trade-offs by designing multiple alternatives for subsystems/components (Sobek et al., } \\
\text { c. 1999) } \\
\text { c. Schedule time for innovation and problem solving while the set of alternatives is broad (Morgan } \\
\text { and Liker,2006; Ward, 2007) } \\
\text { d. Ensure many possible subsystem combinations to reduce the risk of failure (Ward, 2007) } \\
\text { e. Extensive prototyping (physical and parametrical) of alternatives to test for cost, quality, and } \\
\text { ferformance (Ward et al., 1995; Sobek et al.., 1999; Morgan and Liker, 2006; Ward, 2007) } \\
\text { f. Perform an aggressive evaluation of design alternatives to increase knowledge and rule out } \\
\text { g. Information goes into a trade-off knowledge base that guides the design (Ward, 2007) } \\
\text { h. Communicate sets of possibilities (Ward et al.,, 1995; Sobek et al., 1999; Morgan and Liker, } \\
\text { 2006) }\end{array}$ \\
\hline $\begin{array}{l}\text { 4. Integrate by } \\
\text { intersection }\end{array}$ & $\begin{array}{l}\text { a. Look for intersections of feasible sets, including compatibility and interdependencies between } \\
\text { subsystems (Sobek, 1999; Morgan and Liker, 2006; Ward, 2007) } \\
\text { b. Impose minimum constraints: deliberate use of ranges in specification and initial dimensions } \\
\text { should be nominal without tolerances unless necessary (Sobek et al., 1999) } \\
\text { c. Seek conceptual robustness against physical, market, and design variations (Sobek et al., } \\
\text { d1999; Ward, 2007) } \\
\text { d. Concurrent consideration of lean product design and lean manufacturing (Sobek et al., 1999) }\end{array}$ \\
\hline $\begin{array}{l}\text { 5. Establish feasibility } \\
\text { Before commitment }\end{array}$ & $\begin{array}{l}\text { a. Narrow the sets gradually while increasing detail: functions narrow their respective sets based } \\
\text { on knowledge gained from analysis (Ward, 2007) } \\
\text { b. Delay decisions so that they are not made too early or with insufficient knowledge (Sobek et al., } \\
\text { c. } 1999 \text {; Ward, 2007) } \\
\text { Design decisions should be valid for the different sets and should not be effected by other } \\
\text { dubsystems (Sobek et al., 1999) } \\
\text { d. Stay within sets once committed and avoid changes that expand the set (Sobek et al., 1999) } \\
\text { e. Control by managing uncertainty at process gates (Sobek et al., 1999) } \\
\text { f. Manufacturing evaluation of the final sets and dictation of part tolerances (Sobek et al., 1999) } \\
\text { g. Manufacturing begins process planning before a final concept has been chosen and thus act on } \\
\text { incomplete information (Sobek et al., 1999) } \\
\text { h. Delay releasing the final hard specification to major suppliers until late in the design process } \\
\text { (Ward, 2007) }\end{array}$ \\
\hline
\end{tabular}

Table 1. SBCE Principles ([32] and [30]) 


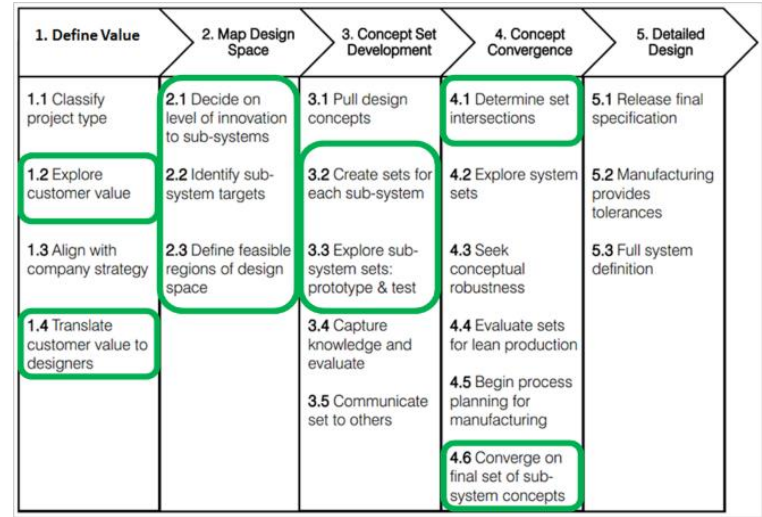

Figure 2. The SBCE process model ([2] and [32])

\section{SBCE industrial case study}

The application of the SBCE process model has been demonstrated based on the real case study in collaboration with a leader company in the manufacturing of electronic access control systems. The collaborator company has been selected due to its continuous production of innovative products which add value to the customer and the range of services. The aim of the case study is to demonstrate the application and validation of the SBCE process shown in Figure 2. In addition, it also demonstrates that SBCE could address the PD challenges encountered in the collaborator company. These challenges have been identified via a formal LeanPPD performance measurement study [3] that is outside the scope of this paper. Examples of such PD challenges are:

1. There is a need to have a clear plan to improve the current PD process with emphasis on eliminating wasteful activities

2. Enhancing the current collaboration between design and manufacturing as well as with key suppliers.

3. Providing a larger space for exploring design alternatives and innovation.

4. Improving the practices of different formal design tools and methods.

5. Providing the designers and engineers with the suitable knowledge environment to support decision making throughout the PD process.

6. Reuse of knowledge gained from previous projects.
Since the case study is using real engineering data, all the sensitive information has been modified or eliminated.

Access control system is the selective restriction of access to a place or other resource. Such a system consists of several subsystems and components as illustrated in Figure 3; A) Tokens (cards and key-fobs), B) Reader, C) Control unit, D) Lock, E) Door, and F) Exit button. In this type of access control system, the identification is based on credentials instead of using mechanical keys. There is a wide range of credentials; the most typical are access cards and key-fobs.

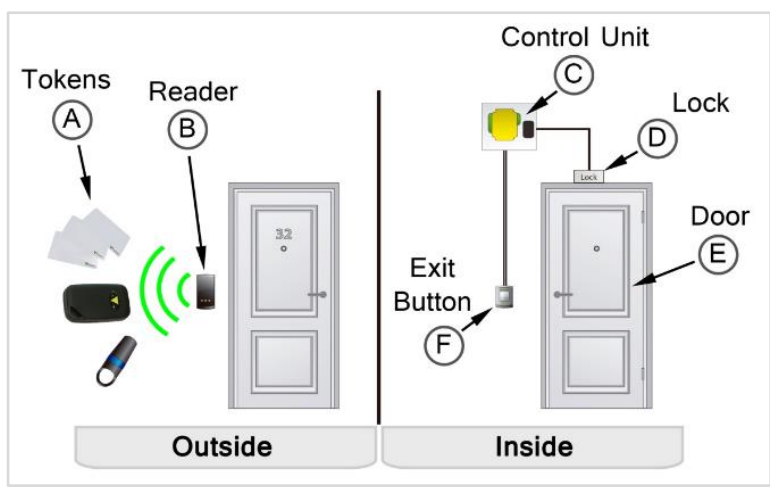

Figure 3. Access control system

The product studied in this case study is commonly known as "reader" (Figure 3-B) and it is an important part of an electronic access control system. The task of the "reader" is to identify the different users trying to access the system and to send this information to another device which verifies if the users are allowed to have access. When the token (A) is close, it can be perceived by the "reader" (B). The interaction between $(\mathrm{A})$ and $(\mathrm{B})$ relies on radio frequency: the token works as an inductor, modifying an electromagnetic field created by the "reader". The signal perceived is sent to the control unit (C), where it is analysed in order to take access decisions. If the token is valid, the control unit will send an indication to the lock (D) in order to open the door (E). In case of using an exit button (F) the door is unlocked without requiring any credential.

The most important characteristic of the "reader"- which is the physical product that has been used to demonstrate the SBCE- is to be vandal resistant; which means, to be resistant to 
different types of damage. For instance, removal of the "reader" by hand, striking the "reader" with any object, burning the case with fire, and spoil with liquid, sand or stones. Other important features in this "reader" are the ability to capture a wide range of credentials and the ease of installation and maintenance.

Industrial case study was conducted by systematicly using the SBCE process model in Figure 2. It is quite a comprehensive model which consists of several activities. Based on variable process requirements, every single project for product development may implement different set of activities from the SBCE model. Thus, this case study also follows the relevant SBCE activities as highlighted within the boxes in Figure 2. The following paragraphs guide the optimal design of "vandal resistant reader" through the SBCE process model.

\section{Phase 1 Define Value:}

The initial concept of the "reader" is defined in "Define Value" stage, which has the following SBCE activity;

\subsection{Explore customer value}

In order to understand the collaborator company's customer needs, the values of the customer were explored thoroughly as shown Figure 4. The key value, that customers required, was a vandal resistant "reader". The values were extracted through face to face interviews and brainstorming sessions with designers and engineers in the collaborator company (Figure 4-A). An extensive list of key values were identified as illustrated in Figure 4B. These 26 values were to be used in determining design criteria to support the evaluation of the alternative designs of the "reader".

In order to ensure that customer needs are fully addressed and accurately understood, values with similar objectives were classified into a singular value as a category. For example, four values were selected from the list in Figure 4-B:

- value number 4 The product must be saved, and should not give access to people that do not have valid card,

- value number 5 the system should not be easily hacked to ensure safety,
- value number 25 The product should be resistant to vandalism without affecting normal working

- value number 26 The product has to be vandal resistant without paying attention to the appearance.

Although these four values are individually exclusive, they serve to the same purpose which is ensuring the security, and protecting the "reader". Therefore, four values were classified in one category "Security and Protection". Similarly, the rest of the values have been classified as shown in Figure 4-C, namely; 1. safety, 2. security and protection, 3. reliability, 4. cost, 5. connection, 6. user friendly and 7 . product size. These were considered as high importance values since they directly address the customer requirements. These requirements are resistance to vandalism, ability to capture a wide range of credentials, and ease of installation and maintenance. Other values were considered as low importance due to indirect effect on the customer requirements. However, achieving the high importance values would end up with improvement on low importance values.

After the classification, the values were prioritised using the Analytical Hierarchy Process (AHP) method. The AHP matrix helps to calculate the loads of each category's importance [10], [54], [22]. The AHP method was implemented with the input from technical knowledge of the collaborator company's engineers.

Any type of product should ensure safety which cannot be traded off. Therefore, "safety" value was evicted from the analysis and became a denominator factor. Six high-importance values were prioritised as illustrated in Figure 4D. "Security and Protection" calculated as the first priority $(38 \%)$ followed by reliability $(27 \%)$. The results of the AHP helped to identify the "key value attributes" as illustrated in Figure 4-E. These are; 1) Security and protection, 2) Cost, 3) Reliability. The most priority key value attributes consist of the $77 \%$ of the all highimportance values. The loads for the key value attributes were re-calculated using the AHP method as follows:

Security and protection: $(0.38 / 0.77) \times 100$ $\%=49 \%$ (approx.)

Reliability: $(0.27 / 0.77) \times 100 \%=35 \%$ (approx.)

Cost: $(0.12 / 0.77) \times 100 \%=16 \%$ (approx.) 


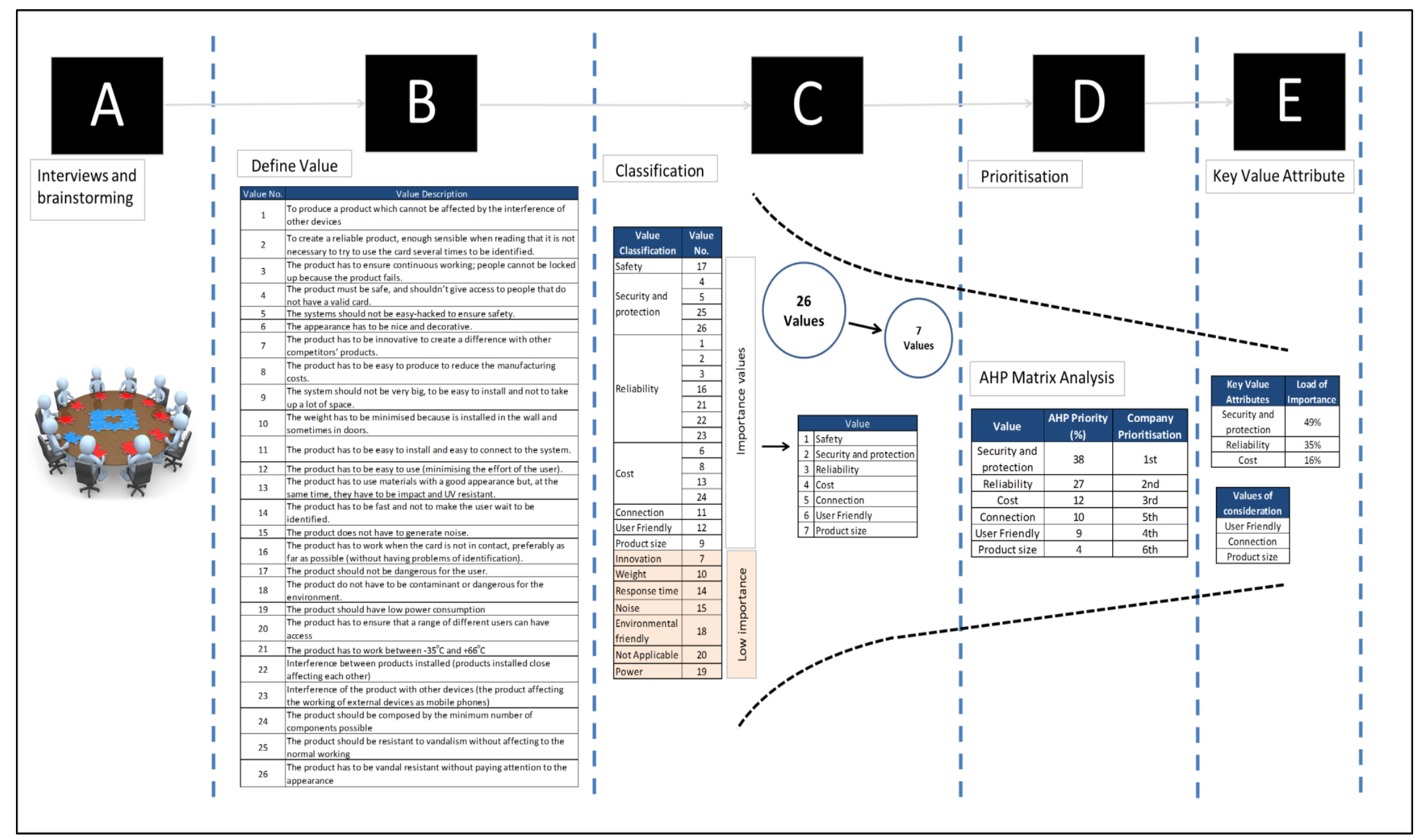

Figure 4. The different sub-activities and their results of the SBCE activity of 1.2 "explore customer value" 
The reason for re-calculation was to have a feasible number of values to improve. A large number of criteria might cause a failure in fulfilment of the expectations. Nevertheless, the values remaining (connection, user friendly and product size) were designated as values of consideration and despite the fact that the values are not the key values, it still could satisfy the aim of the "reader" project.

\subsection{Translate customer value to designers}

The system targets should be defined in order to clarify how the value attributes will be achieved. These targets should be reviewed at the subsystem level to ensure the correct flow down on system targets. System targets are measurable/numeric values of key value attributes; however, several targets may not be represented by a numerical value. For instance, the system targets of security and protection were defined as: 1) The "reader" must be damage-resistant which can withstand a hit-force of up to 4500 Newtons; 2) The "reader" shall comply with the V-0 fire resistant standard rating, which can withstand the flaming combustion for more than 10 seconds or the total flaming combustion time shall not exceed 50 seconds for 10 times repetitive flame application; 3) The "reader" must be well protected in terms of accessibility; 4) The "reader" must survive the IK9 resistance index for impact which equal to 5 kilograms mass impact; 5) The "reader" must survive the IPX6 rating index protection against intrusion of dust or liquid which is equal to 100 litres per minutes spray of water at any direction for at least 3 minutes. The same approach has been used for the other values in defining the system targets and displayed in Table 3.

\begin{tabular}{|c|c|c|}
\hline $\begin{array}{c}\text { Company } \\
\text { Prioritisation }\end{array}$ & Customer value & System Target \\
\hline 1 & $\begin{array}{l}\text { Security and } \\
\text { protection }\end{array}$ & $\begin{array}{l}\text { 1. The "reader" must be damage-resistant (approx. } 4500 \mathrm{~N}) \text {. } \\
\text { 2. The "reader" must ensure V-0 (flammability standard). } \\
\text { 3. The "reader" internal system must be well protected (in terms of } \\
\text { accessibility). } \\
\text { 4. The "reader" must ensure IK9 rating (impact protection). } \\
\text { 5. The "reader" must ensure IPX6 rating (ingress protection). }\end{array}$ \\
\hline 2 & Reliability & $\begin{array}{l}\text { 6. } 250,000 \text { activations during the product life ( } 5 \text { years). } \\
\text { 7. No more than } 5 \text { failures per hour. } \\
\text { 8. Minimise the interferences. } \\
\text { 9. The "reader" must work between }-40^{\circ} \text { Celcius and }+80^{\circ} \text { Celcius } \\
\text { 10. Minimum operational distance of } 1 \mathrm{~cm} \\
\text { 11. Maximum operational distance of } 5 \mathrm{~cm}\end{array}$ \\
\hline 3 & Cost & $\begin{array}{l}\text { 12. The "reader" price must not exceed } £ x \text { (value not given). } \\
13 \text {. To re-use } 80 \% \text { from the existing "reader". }\end{array}$ \\
\hline
\end{tabular}

Table 3. System targets of the Key Value Attributes (KVA) of the "reader" case study

Phase 2 Map Design Space:

This stage identifies the scope and feasible regions of the "reader" design.

\subsection{Decide on level of innovation to subsystems}

In order to decide on the level of innovation, the product was broken down into its subsystems as shown in Figure 5-A. "Reader" consists of seven subsystems; (1) Front cover, (2) the "reader" module -which has two separate sub-subsystems (2.a-Housing front cover and 2.b-Housing back plate); , (3) Coil, (4) Main PCB, (5) 


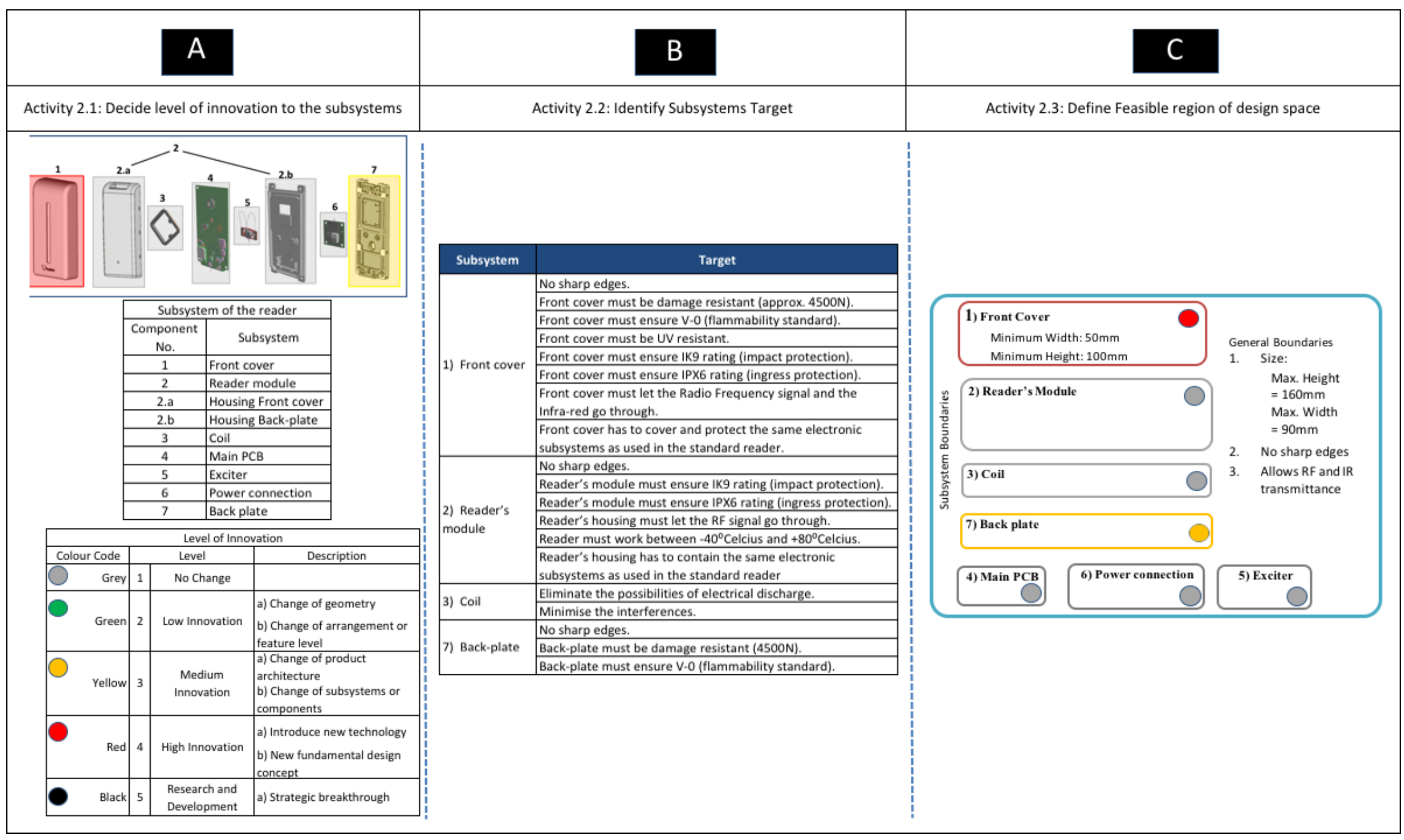

Figure 5. The different sub-activities and their results of the SBCE activity 2 "Map design space" 
Exciter, (6) Power connection, and (7) Back plate.

The level of innovation is coded with colours for different subsystems to provide a simple communication among the designers, engineers and customers. As illustrated in Figure 5-A:

- Grey colour is for Level 1 innovation which means no change to be made on the product,

- Green is for Level 2- represents a low innovation,

- Yellow is for Level 3- represents medium innovation,

- Red is for Level 4- represents high innovation,

- Black is for Level 5- represents a need for research and development.

For instance, the level of innovation for the front cover (1) has been classified with a red colour code (Level 4) where the subsystem requires a new technology or new design concept to be implemented. The front cover (1) will be the first subsystem to receive any force that might damage the "reader". Therefore, it needs a new design concept that can be resistant to damage due to vandal actions. Regarding the back plate (7), it is attached to the wall and also to the front cover (1). It might also be affected by the vandalism act, thus, the back plate needs a medium level of design changes to enhance its physical performance to withstand forces that may possibly damage the "reader". Other subsystems such as the reader module (2), Housing front cover (2.a), Housing back plate (2.b), Coil (3), Main PCB (4), Exciter (5), and Power connection (6) are coded with a "Grey" colour which do not require any change in this project. The existing designs remain the same as they do not have impact in the level of protection for the "reader" against vandalism.

\subsection{Identify subsystem targets}

In the activity 2.2 "Identify subsystem targets", the feasible target for each subsystem is defined to prevent over-engineering while encouraging the necessary innovation and improvement. Some of the targets were adapted from the system target in the "Define value" stage, others were defined as a new target in order to ensure it meets the key value attributes; security and protection, reliability, and cost. The subsystem targets for the front cover (1) are listed as follows:

- No sharp edges,

- Must be damage resistant which can withstand the hit force up to 4500 Newton,

- Must withstand the V-0 fireresistance rating,

- Must be UV resistant,

- Must survive in the IK9 resistance index for impact which equal to 5 kilogram mass impact,

- Must survive in the IPX6 rating index protection against intrusion of dust or liquid,

- Must let the Radio Frequency signal and the Infra-red to go through

- Must be able to cover and protect the same electronic subsystems as used in the standard "reader".

Similarly, the rest of the subsystem targets are listed accordingly as illustrated in Figure 5B.

\subsection{Define feasible region of design space}

The design space is a boundary for designers and engineers to explore and communicate with many alternative conceptual design solutions. Figure 5-C illustrates the overall design space for the "reader" case study as well as its subsystem that have a level of innovation; namely front cover (1) and back plate (7). The following are the "reader" boundaries:

General boundaries:

1. Size; maximum height is $160 \mathrm{~mm}$ and maximum width is $90 \mathrm{~mm}$,

2. Use of rounded edges,

3. Allows Radio Frequency (RF) and Infra-red (IR) transmittance, therefore the new design must allow RF and IR signal receiving. This is particularly related to the "front cover" design as excessive thickness or the use of certain materials may significantly affect RF and IR signal receiving.

Subsystem boundaries for front cover (1):

1. Minimum height is $100 \mathrm{~mm}$ and the minimum width is $50 \mathrm{~mm}$. These have been identified in order to create an appropriate space for the other subsystems with no modification to fit 


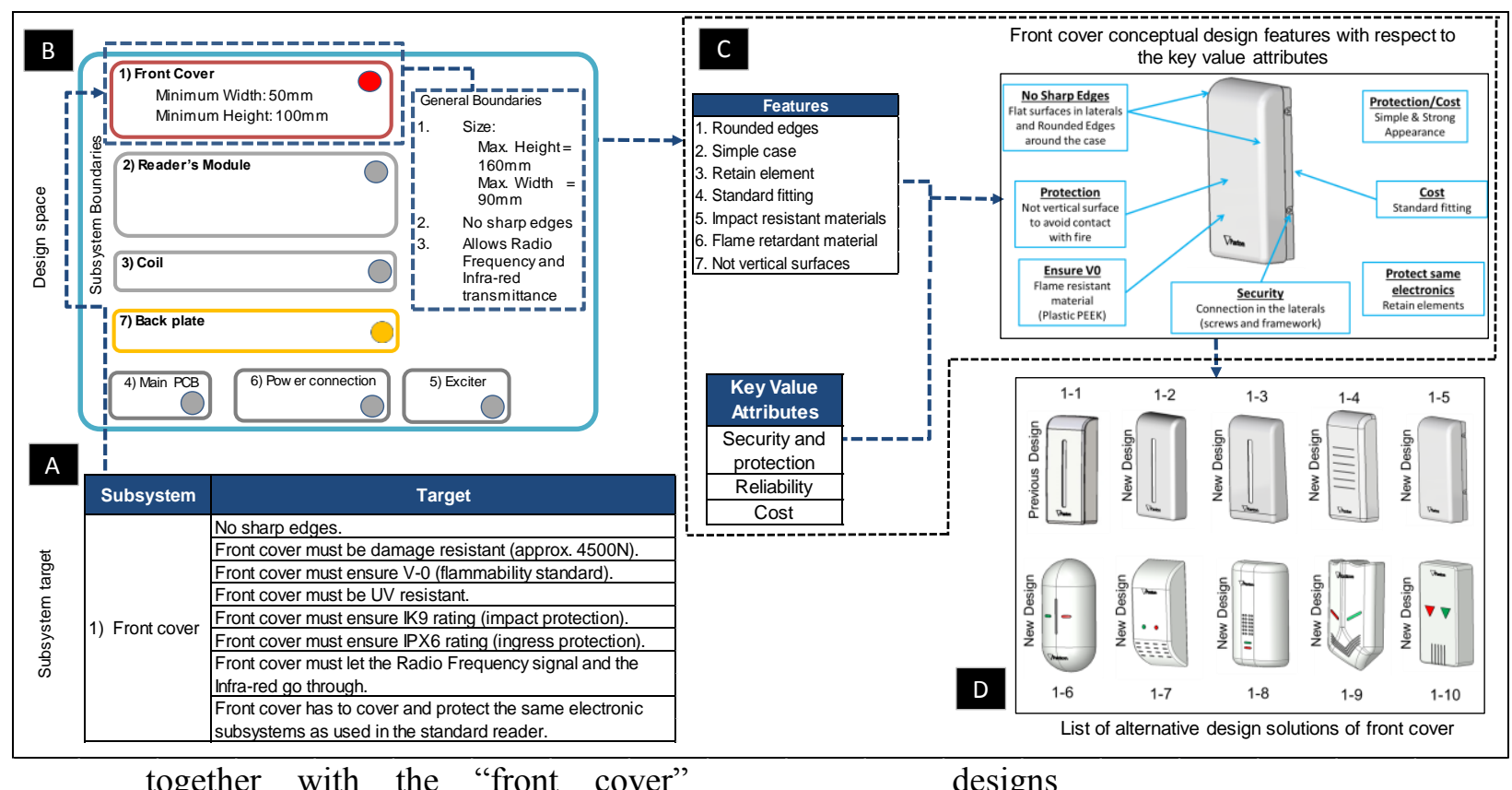

together with the "front cover"

designs.

Figure 6. The SBCE activity 3.2 "Create set for each sub-system"

It is important not to impose too many constraints on the design space, as this may limit innovation of the product.

\section{Phase 3 Develop Concept Sets:}

In this phase, the set of possible conceptual design solutions was developed for each subsystem of the "reader".

\subsection{Create sets for each subsystem}

The main objective of this activity is to propose alternative design solutions. The possible design solutions are developed specifically for the front cover (1) and back plate (7). The following paragraph explains how the front cover (1) is designed and proposes a set of possible conceptual design solutions as illustrated in Figure 6.

Figure 6-A shows the subsystem targets. They are taken into consideration, while generating the new alternative designs. Furthermore, the defined boundary in activity 2.3 "Define feasible region of design space" should also be considered in order to guide the "reader" design process. General and subsystem boundaries are illustrated in Figure 6-B. The new alternative designs of the front cover should have features that address both the identified key value attributes and the subsystem targets. These features are illustrated in Figure 6-C, namely, rounded edges, simple case, retain element, standard fitting, impact resistant materials, flame retardant material, and no vertical surfaces. Considering the key value attributes, subsystem targets, general boundaries and subsystem boundaries, a set of ten design-concepts were generated for the front cover. Figure 6-D demonstrates ten designs, nine of which are new designs.

Likewise, five different design-concepts were created for the back plate. Design-set includes one previous design using the same approach for the front cover. Figure 7 illustrates the set of conceptual design solutions for the back plate. The rest of the reader's subsystems shown in Figure 5-A keep the same previous design without any change. Thus, the design space of the "reader" could generate 50 potential solutions. This is calculated as follows:

10 (front cover) x 5 (back plate) x 1 (reader's module) x 1 (coil) x 1 (main PCB) x 1 (exciter) $\mathrm{x} 1$ (power connection $)=50$.

Figure 7. Set of conceptual design solutions of the

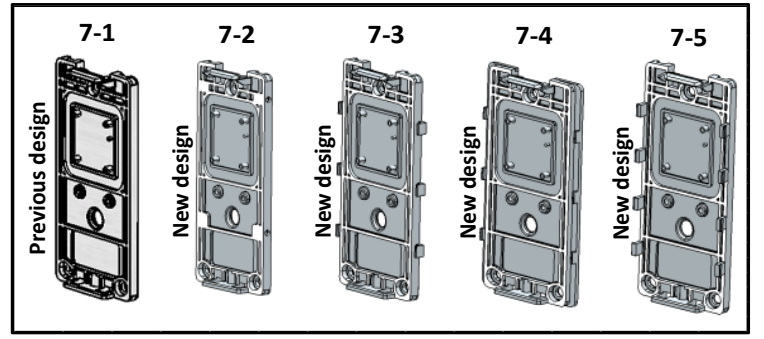




\section{back plate component}

\subsection{Explore subsystem sets: prototype \& test}

The purpose of activity 3.3 "Explore subsystem sets: prototype \& test" is to analyse the conceptual solutions in order to evaluate their reliability. This analysis has been focused on the structural and thermal properties which fit the aim of the "reader" case study. Tests were applied to the front cover and back plate. Figure 8 illustrates an example of structural and thermal analysis for one of the design options of the front cover (Design option 1-9 in Figure 6-D). Analysis showed that Design 1-9 had a weak area to the right of the centre. Therefore, modifications were needed in this design option, otherwise it would considered as an infeasible solution. Gaining such a knowledge in this stage of the product development process would give the opportunity to designers to innovate and save time until they reach an optimal solution.

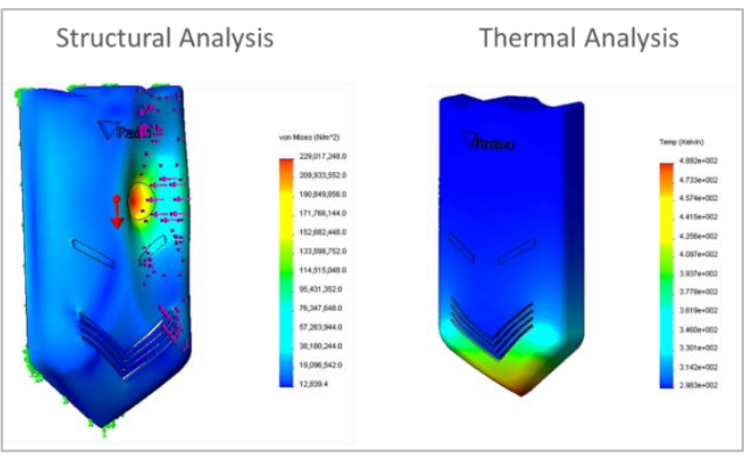

Figure 8. Examples of structural and thermal analysis for front cover 1-9

\section{Phase 4 Concept Convergence:}

At this stage, integration of the subsystems was explored based on the knowledge produced. Any infeasible alternatives were discarded so that the final optimal "reader" design could be allowed to progress until the completion of the design stage.

\subsection{Determine set intersections}

The final set of "reader" systems was generated (see Figure 9-A) by integrating the set of solutions that was presented in SBCE activity 3.2 "Create set for each subsystem". From the 50 potential solutions, not all are compatible to become a "reader". Therefore, an intersection matrix was used to analyse the feasibility of the "reader" configurations. The intersection matrix, as illustrated in Table 4, has as many columns as rows; each of them represents a subsystem of the "reader": 1) Front cover which has 10 alternative solutions (see Figure 6-D), 2) Reader's module 3) Coil, 4) Main PCB, 5) Exciter, 6) Power connection, and 7) Back plate which has 5 alternative solutions (see Figure 7). The intersection matrix evaluates the combination between the elements in the columns and the elements in the rows according to the scores which are as follows:

- Score 1: Options that can be integrated without any modification,

- Score 3: Options that need modification to be integrated but provide potential benefits,

- Score 5: Options that cannot be integrated because they need a high level of modification.

Combinations that require a high level of modification are discarded from the alternative list. Subsystems that create conflicts with other subsystems that could not be changed are also discarded. This is done via brainstorming sessions between designers and engineers. For instance, there was a conflict of assembling and integrating the back plate (7-5) with both the reader's module (2) and the Main PCB (4). Therefore, the back plate (7-5) was discarded. The same evaluations have been made for the other sets which have scored a 5 as illustrated in Table 4-A. Since there is no modification required for the Reader module, Coil, Main PCB, Exciter, and Power connection, the sets are kept to progress into detailed designs as shown in Table 4-B. In addition, during brainstorming sessions, decisions have been made to further progress the detail for design solutions 7-2 (of the back plate) as it requires small modifications. From the intersection matrix, the reader's configurations were reduced from 50 to 19 feasible configurations as shown in Table 4B. 


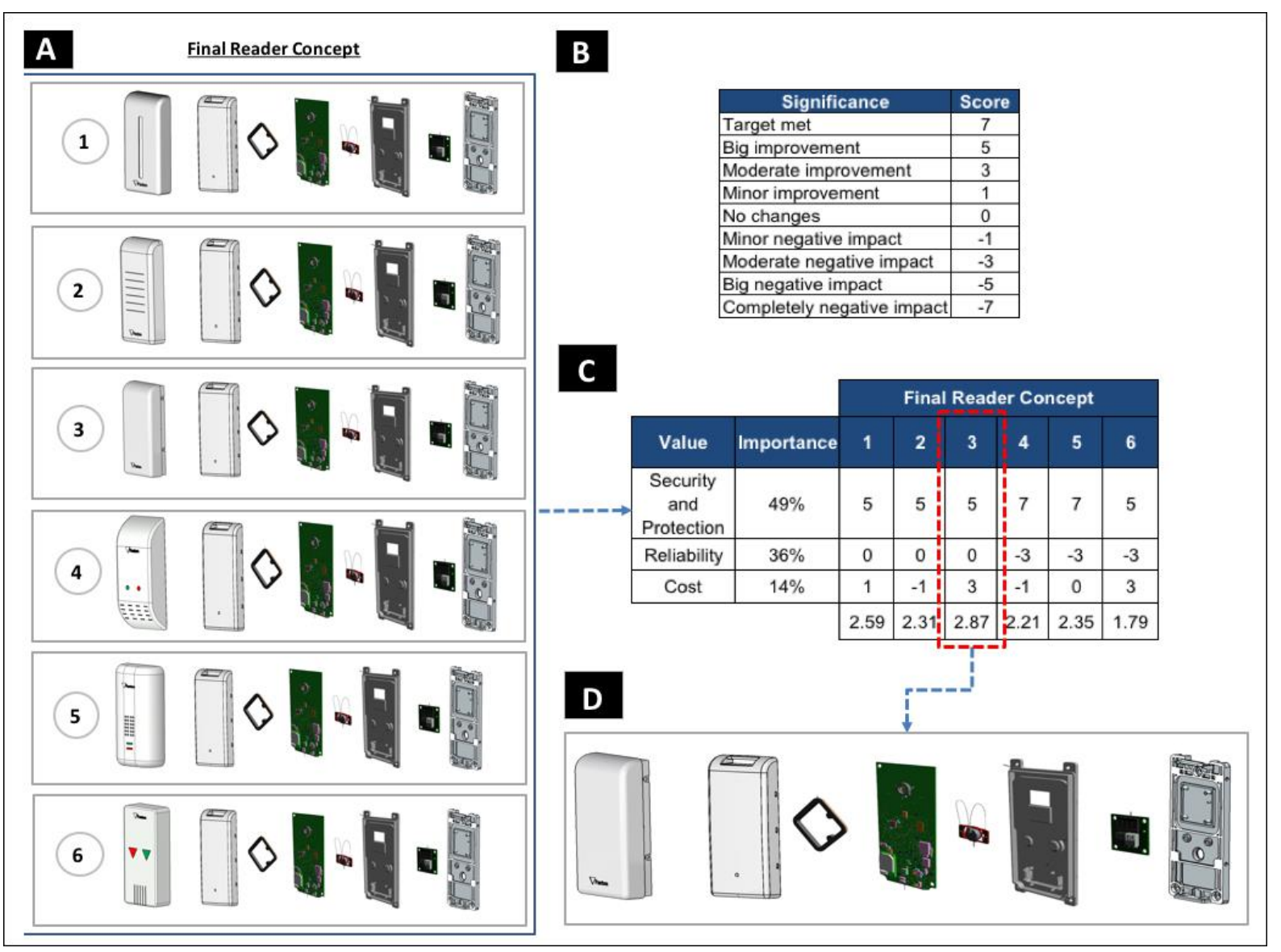

Figure 9. The SBCE activity 4.6 "Converge on final set of system" to select the final "reader" system

\subsection{Converge on final set of subsystem concepts}

In activity 4.6 "Converge on the final set of system", an aggressive narrowing process was carried out to reduce the feasible "reader" configurations from 19 to 6 solutions. Based on brainstorming sessions within the design team, several criteria which associated to the key value attributes of the "reader" have been selected and evaluated as shown in Table 5. For example, the combination of front cover (1-1) and back plate (7-1) could give significant cost-effective design option since it comes from previous design. There is no issue with the manufacturability since it used an existing mould where no modification is required. The complexity of the assembly is also minimal due to its simple snapfit assembly technique. However, the design is not capable to withstand the fire burn due to its material. It is also not able to survive any high impact forces due to its snap-fit assembly technique. Even though cost and complexity criteria are meeting the target, the security and protection, and reliability are failing to meet the aim of the vandal resistant "reader". Hence, the combination was discarded from the list of alternatives. Similarly, the rest of the combinations have been evaluated which then helped to also narrowing as shown in Table 5 and Figure 9-A. 


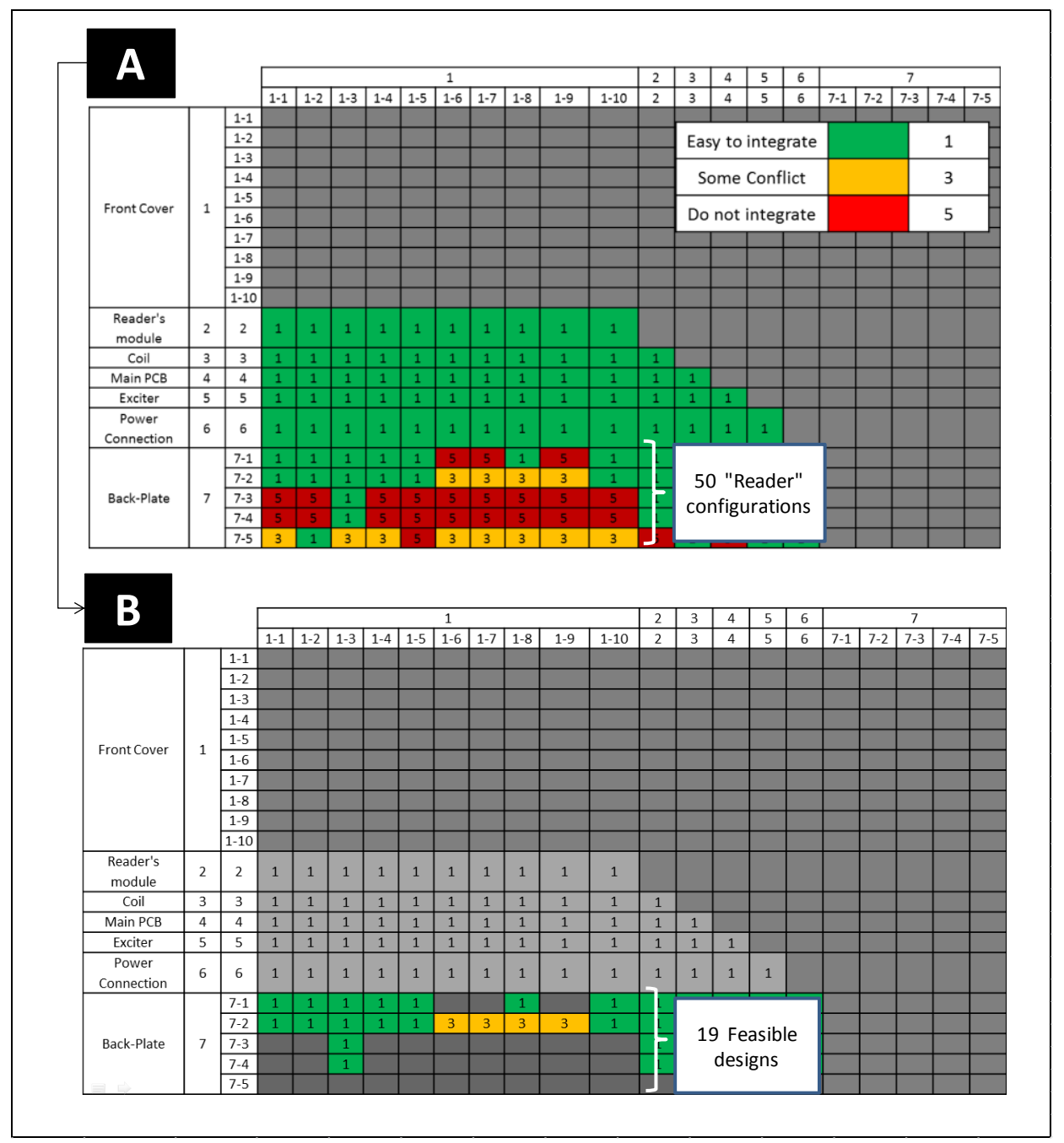

Table 4. The intersection matrix of the alternative design solutions of the "reader" component

In order to define the optimal solution of the "reader", the PUGH matrix [45] was used to evaluate the six selected alternative system solutions in order to reach the final optimal solution of the "reader" system. The performance scale from 7 to -7 was used to indicate the score. The score is arranged in the odd number order where 7 as the highest score represents that the targets are met, zero represents no changes being made, -7 represents completely negative impact, and other scores are arranged in between as illustrated in Figure 9-B. The different criteria can be weighed according to their importance as shown in Figure 9-C. Thereafter, each of the potential options are scored and also multiplied by their weighting in order to produce a result. For instance, the "reader" system concept 3 which is based on the configuration of front cover (1-5) and back plate (7-2) has been evaluated as follows:

- "Safety and protection" is scored as 5 , which means big design improvements were made for the front cover.

- "Reliability" is scored 0 , no change is required in terms of the ability of the "reader" to transmit the radio frequency and infra-red signal.

- "Cost" is scored as 3, which provides a moderate improvement to the cost reduction. 


\begin{tabular}{|c|c|c|c|c|c|c|}
\hline \multicolumn{2}{|c|}{ Combination } & \multicolumn{5}{|c|}{ Evaluation Criteria } \\
\hline \multirow{2}{*}{$\begin{array}{l}\text { Front } \\
\text { Cover }\end{array}$} & \multirow{2}{*}{$\begin{array}{l}\text { Back } \\
\text { Plate }\end{array}$} & \multirow{2}{*}{ Cost } & \multicolumn{2}{|c|}{ Complexity } & \multirow{2}{*}{ Security } & \multirow{2}{*}{ Decision } \\
\hline & & & Manufacturability & Assembly & & \\
\hline $1-1$ & $7-1$ & $\begin{array}{l}\text { No modification in } \\
\text { moulds }\end{array}$ & $\begin{array}{l}\text { Plastic, no modification } \\
\text { required and existing } \\
\text { moulds }\end{array}$ & $\begin{array}{c}\text { Simple } \\
\text { assembly } \\
\text { (Snap-fit) }\end{array}$ & $\begin{array}{l}\text { 1. Not fire resistant because of the } \\
\text { material. } \\
\text { 2. Possible weaknesses by pulling } \\
\text { from the laterals due to fitting. } \\
\text { 3. Design is easy to hold thus it is } \\
\text { subject to pulling. }\end{array}$ & $\begin{array}{l}\text { Discarded } \\
\text { Cost effective but } \\
\text { there is no } \\
\text { improvement in fire } \\
\text { resistance }\end{array}$ \\
\hline $1-1$ & $7-2$ & $\begin{array}{l}\text { Modification in } \\
\text { moulds to add screws } \\
\text { (addition of slider) }\end{array}$ & $\begin{array}{l}\text { Plastic, modifications in } \\
\text { mould required (using the } \\
\text { same mould but adding } \\
\text { slides) }\end{array}$ & $\begin{array}{c}\text { Simple } \\
\text { assembly } \\
\text { (Screws) }\end{array}$ & $\begin{array}{l}\text { 1. Not fire resistant because of the } \\
\text { material. } \\
\text { 2. Improved fitting in laterals } \\
\text { (screws difficult to hide) } \\
\text { 3. Design is easy to hold thus it is } \\
\text { susceptible to pulling. }\end{array}$ & $\begin{array}{l}\text { Discarded } \\
\text { Modifications required } \\
\text { are expensive for the } \\
\text { benefits obtained }\end{array}$ \\
\hline $1-2$ & $7-1$ & $\begin{array}{l}\text { Simple case } \\
\text { Mould easy to } \\
\text { manufacture but } \\
\text { should be created } \\
\text { from scratch }\end{array}$ & $\begin{array}{l}\text { Plastic, mould required. } \\
\text { Uniform thickness }\end{array}$ & $\begin{array}{c}\text { Simple } \\
\text { assembly } \\
\text { (Snap-fit) }\end{array}$ & $\begin{array}{l}\text { 1. Possible weaknesses by pulling } \\
\text { from the laterals due to fitting. } \\
\text { 2. Structural analysis simulated } \\
\text { large displacements (specifically } \\
\text { in the central hole) }\end{array}$ & $\begin{array}{l}\text { Discarded } \\
\text { Required a new } \\
\text { mould, but security is } \\
\text { not ensured due to } \\
\text { reuse of the back plate } \\
\text { 7-1. Additionally, the } \\
\text { concept is weak } \\
\text { against impacts. } \\
\end{array}$ \\
\hline $1-5$ & $7-2$ & $\begin{array}{l}\text { Difficult medium } \\
\text { mould; should use a } \\
\text { slider and should be } \\
\text { created from } \\
\text { scratch }\end{array}$ & $\begin{array}{l}\text { Plastic, mould required. } \\
\text { Uniform thickness. }\end{array}$ & $\begin{array}{c}\text { Simple } \\
\text { assembly } \\
\text { (Screws) }\end{array}$ & $\begin{array}{l}\text { 1. Structural analysis simulated } \\
\text { only small displacements } \\
\text { occurred (thinner area in centre) } \\
\text { 2. Need of framework to make the } \\
\text { part easy to manufacture }\end{array}$ & \begin{tabular}{|l} 
Kept \\
Option to consider
\end{tabular} \\
\hline
\end{tabular}

Table 5. A portion of the evaluation of the 19 alternative potential "reader" system solutions. Narrowing down from 19 system solutions to 6

Therefore, the PUGH matrix result for this system configuration is calculated as follows:

$(49 \%$ x 5$)+(35 \%$ x 0$)+(16 \%$ x 3$)=2.93$.

The rest of the configurations are analysed and calculated accordingly as depicted in Figure 9-C. The solution with the highest score was recommended to become a preferred solution. As a result, the optimal solution of the "reader" system is concept 3 (shown in Figure 9-D) which is going to be released to the final specification in the detailed design on phase 5 in the SBCE process model.

\section{Discussion}

The literature review in section 2 showed two main groups of researches; the one that mentions and emphasises the importance of SBCE, however, does not present detailed work. The second group developed and acclaimed Lean Product Development (LeanPD) frameworks in the form of tables that have got several elements adopted from other LeanPD and product development based literature, without addressing SBCE application. [58] work is still the main reference of SBCE. Several research attempts have been done to help to drive SBCE through engineering relationship through the incorporation of fuzzy set theory/logic and the automated analysis of design parameters by means of mathematical algorithms. However, this type of work seems to stay in its research level without mentioning the impact on real industrial applications.

The paper presented a validation of the developed SBCE process model via a real industrial case study of access control. This case study benefited the company, by enhancing its current product development process by providing a space to explore alternative designs from different angles i.e. security and protection, 
reliability, and cost. The SBCE approach guided the development of a "reader" access control product with the right design and engineering activities as well as the associated tool and method to enable the application of the different activities.

The SBCE approach provided a suitable knowledge environment to support decision making throughout the product development process. The innovation and knowledge creation level has increased where 50 system design configurations were identified via the application of the SBCE process model in the case study. In terms of product performance, the safety and protection for the "reader" are expected to increase to $71.4 \%$ from the previous "reader". The percentage value of product performance (safety and protection) of the "reader" are based on the structural analysis using the Solidwork software by comparing the stress value of the existing design (real-life product) and the optimal design (from the SBCE approach). Due to confidentiality, the value can only be expressed by percentage to show the improvement. The cost is expected to be reduced up to $43 \%$ for the "reader" product with configuration of front cover 1-5 and back plate 7-2 shown in Figure 9-C. The cost saving was realised from the actual implementation of SBCE on real product. The expected cost reduction mentioned are based on the projection with respect to the following design condition; 1) A design solution with a thicker and wider front cover will require more material, which leads to an increase in cost; 2) The manufacturing cost of the product is depending on the type and amount of the material used. Due to confidentialilty the cost savings are mentioned in percentage value.

\section{Conclusion}

The research presented in this paper provides a detailed, well-structured Set-Based Concurrent Engineering (SBCE) process model based on well researched and identified principles, and its systematic application in a real industrial setting. SBCE is the core enabler of the LeanPPD model as it represents the process model that should be followed in developing a product. SBCE focuses on value creation, provision of a knowledge environment, continuous improvement, and process that encourage innovation through the exploration of sets of alternative solutions. A systematic review has been conducted in which the various approaches of lean PD have been analysed to evaluate their adoption and application of lean principles, as well as the importance of applying SBCE. The research proves that the SBCE has got all the potential to address current product development challenges in producing high quality products in a shorter time and in a cost effective manner. Future work may consider a development of the business case for the SBCE as it could facilitate a valid justification of the expected benefits.

\section{References}

[1] Al Handawi, K., Andersson, P., Panarotto, M., Isaksson, O., \& Kokkolaras, M. (2021). Scalable SetBased Design Optimization and Remanufacturing for Meeting Changing Requirements. Journal of Mechanical Design, 143(2). https://doi.org/10.1115/1.4047908

[2] Al-Ashaab, A., Golob, M., Attia, U. M., Khan, M., Parsons, J., Andino, A., Perez, A., Guzman, P., Onecha, A., Kesavamoorthy, S., Martinez, G., Shehab, E., Berkes, A., Haque, B., Soril, M., \& Sopelana, A. (2013). The transformation of product development process into lean environment using set-based concurrent engineering: A case study from an aerospace industry. Concurrent Engineering Research and Applications, 21(4). https://doi.org/10.1177/1063293X1349 5220

[3] Al-Ashaab, A., Golob, M., Urrutia, U. A., Gourdin, M., Petritsch, C., Summers, M., \& El-Nounu, A. (2016). Development and application of lean product development performance measurement tool. International Journal of Computer Integrated Manufacturing, 29(3). https://doi.org/10.1080/0951192X.201 5.1066858

[4] Ammar, R., Hammadi, M., Choley, J. Y., Barkallah, M., Louati, J., \& Haddar, M. (2019). Narrowing the set 
of complex systems' possible design solutions derived from the set-based concurrent engineering approach. Concurrent Engineering Research and Applications, 27(3). https://doi.org/10.1177/1063293X1985 5115

[5] Anand, G., \& Kodali, R. (2008). Development of a conceptual framework for lean new product development process. International Journal of Product Development, 6(2). https://doi.org/10.1504/IJPD.2008.019 240

[6] Araci, Z. C., Al-Ashaab, A., Lasisz, P. W., Flisiak, J. W., Maulana, M. I. I. M., Beg, N., \& Rehman, A. (2017). Trade-off Curves Applications to Support Set-based Design of a Surface Jet Pump. Procedia CIRP, 60. https://doi.org/10.1016/j.procir.2017.0 1.028

[7] Araci, Z. C., Tariq, M. U., Al-Ashaab, A., Braasch, J. H., \& Simsekler, M. C. E. (2020). Creating knowledge environment during lean product development process of jet engine. International Journal of Advanced Computer Science and Applications, 11(5).

https://doi.org/10.14569/IJACSA.2020 .0110509

[8] Araci, Z. C., Al-Ashaab, A., \& Maksimovic, M. (2015). A process of generating trade-off curves to enable set-based concurrent engineering. Proceedings of the European Conference on Knowledge Management, ECKM.

[9] Avigad, G., \& Moshaiov, A. (2010). Set-based concept selection in multiobjective problems involving delayed decisions. Journal of Engineering Design, 21(6). https://doi.org/10.1080/095448208024 59243

[10] Bhushan, N., \& Rai, K. (2007). Strategic Decision Making: Applying the Analytic Hierarchy Process. Interfaces, 35(3).
[11] Blindheim, J., Elverum, C. W., Welo, T., \& Steinert, M. (2020). Concept evaluation in new product development: A set-based method utilizing rapid prototyping and physical modelling. Journal of Engineering, Design and Technology, 18(5). https://doi.org/10.1108/JEDT07-2019-0170

[12] Camarda, C. J., Scotti, S. J., Kunttu, I., \& Perttula, A. (2020). Rapid learning and knowledge-gap closure during the conceptual design phase - rapid R\&D. Technology Innovation Management Review, 10(3). https://doi.org/10.22215/timreview/13 32

[13] Cooper, L. P. (2003). A research agenda to reduce risk in new product development through knowledge management: A practitioner perspective. Journal of Engineering and Technology Management - JET-M, 2O(1-2 SPEC.). https://doi.org/10.1016/S09234748(03)00007-9

[14] Correia, A. T., Stokic, D., \& Faltus, S. (2014). Mechanisms for communication and knowledge sharing for set-Based concurrent engineering. International Journal of Product Development, 19(5-6). https://doi.org/10.1504/IJPD.2014.064 883

[15] Curwen, L. G., Park, J., \& Sarkar, A. K. (2013). Challenges and Solutions of Sustainable Apparel Product Development: A Case Study of Eileen Fisher. Clothing and Textiles Research Journal, $31(1)$. https://doi.org/10.1177/0887302X1247 2724

[16] Du Manoir Geoffroy, L. C., Shruthi, S., Yan, Z., \& Mingze, M. (2019). Architecture and design definition processes: Return of experiment about complementary MBSE tools to model consistent architecture layers and to support design trade-offs through a set based concurrent engineering approach. ISSE 2019 - 5th IEEE 
International Symposium on Systems Engineering, Proceedings. https://doi.org/10.1109/ISSE46696.201 9.8984581

[17] Eckert, C., Isaksson, O., Lebjioui, S., Earl, C. F., \& Edlund, S. (2020). Design margins in industrial practice. Design Science. https://doi.org/10.1017/dsj.2020.19

[18] Elhariri Essamlali, M. T., Sekhari, A., \& Bouras, A. (2017). Product lifecycle management solution for collaborative development of Wearable MetaProducts using set-based concurrent engineering. Concurrent Engineering Research and Applications, 25(1). https://doi.org/10.1177/1063293X1667 1386

[19] Fitzgerald, M. E., \& Ross, A. M. (2019). Artificial intelligence analytics with Multi-Attribute Tradespace Exploration and Set-Based Design. Procedia Computer Science, 153. https://doi.org/10.1016/j.procs.2019.05 .052

[20] Ford, D. N., \& Sobek, D. (2003). Modeling Real Options to Switch Among Alternatives in Product Development. Industrial Engineering.

[21] Georgiades, A., Sharma, S., Kipouros, T., \& Savill, M. (2019). ADOPT: An augmented set-based design framework with optimisation. Design Science, 5. https://doi.org/10.1017/dsj.2019.1

[22] Henry, M., \& Kato, Y. (2011). An assessment framework based on social perspectives and Analytic Hierarchy Process: A case study on sustainability in the Japanese concrete industry. Journal of Engineering and Technology Management - JET-M, 28(4). https://doi.org/10.1016/j.jengtecman.2 011.06 .006

[23] Hoppmann, J., Rebentisch, E., Dombrowski, U., \& Zahn, T. (2011). A framework for organizing lean product development. EMJ Engineering Management Journal, 23(1). https://doi.org/10.1080/10429247.2011 .11431883

[24] Inoue, M., Nahm, Y. E., Okawa, S., \& Ishikawa, H. (2010). Design support system by combination of 3D-CAD and CAE with preference set-based design method. Concurrent Engineering Research and Applications, 18(1). https://doi.org/10.1177/1063293X0936 0833

[25] Inoue, M., \& Suzuki, W. (2019). Universal design considering physical characteristics of diverse users. International Journal of Automation Technology, 13(4). https://doi.org/10.20965/ijat.2019.p051 7

[26] Ishikawa, H., \& Sasaki, N. (2020). A balanced design for plural performances of technology, economy and environment in product design. Procedia Manufacturing, 43. https://doi.org/10.1016/j.promfg.2020. 02.124

[27] Kennedy, M. N. (2003). Product development for the lean enterprise: why Toyota's system is four times more productive and how you can implement it. OakleaPress.

[28] Kennedy, M., Harmon, K., \& Minnock, E. (2008). Ready, Set, Dominate: Implement Toyota's SetBased Learning for Developing Products and Nobody Can Catch You. OakleaPress.

[29] Kerga, E., Taisch, M., Terzi, S., Bessega, W., \& Rosso, A. (2014). Setbased concurrent engineering innovation roadmap (SBCE IR): A case on adiabatic humidification system. International Journal of Design Creativity and Innovation, 2(4).

https://doi.org/10.1080/21650349.2014 .899164

[30] Khan, M. S., Al-Ashaab, A., Shehab, E., Haque, B., Ewers, P., Sorli, M., \& Sopelana, A. (2013). Towards lean product and process development. International Journal of Computer 
Integrated Manufacturing, 26(12). https://doi.org/10.1080/0951192X.201 1.608723

[31] Khan, M. S. (2012). The construction of a model for lean product development. In $P Q D T-U K \&$ Ireland.

[32] Khan, M., Al-Ashaab, A., Doultsinou, A., Shehab, E., Ewers, P., \& Sulowski, R. (2011). Set-based concurrent engineering process within the LeanPPD environment. Advanced Concurrent Engineering. https://doi.org/10.1007/978-0-85729799-0 51

[33] Landahl, J., Levandowski, C., Johannesson, H., \& Isaksson, O. (2016). Assessing producibility of product platforms using set-based concurrent engineering. Advances in Transdisciplinary Engineering, 4. https://doi.org/10.3233/978-1-61499703-0-35

[34] Letens, G., Farris, J. A., \& Van Aken, E. M. (2011). A multilevel framework for lean product development system design. EMJ - Engineering Management Journal, 23(1). https://doi.org/10.1080/10429247.2011 .11431887

[35] Levandowski, C., Michaelis, M. T., \& Johannesson, H. (2014). Set-based development using an integrated product and manufacturing system platform. Concurrent Engineering Research and Applications, 22(3). https://doi.org/10.1177/1063293X1453 7654

[36] Liker, J. K., \& Morgan, J. (2011). Lean product development as a system: A case study of body and stamping development at ford. EMJ Engineering Management Journal, 23(1).

https://doi.org/10.1080/10429247.2011 .11431884

[37] Lopes, K. M., \& Zancul, E. (2019). Application of set-based concurrent engineering principles in $\mathrm{R} \& \mathrm{D}$ project prioritization. Procedia CIRP, 84. https://doi.org/10.1016/j.procir.2019.0 4.194

[38] Madhavan, K., Shahan, D., Seepersad, C. C., Hlavinka, D. A., \& Benson, W. (2008). An industrial trial of a setbased approach to collaborative design. Proceedings of the ASME

Design Engineering Technical Conference, 1(PARTS A AND B). https://doi.org/10.1115/DETC200849953

[39] Maulana, M. I. I. B. M., Al-Ashaab, A., Flisiak, J. W., Araci, Z. C., Lasisz, P. W., Shehab, E., Beg, N., \& Rehman, A. (2017). The Set-based Concurrent Engineering Application: A Process of Identifying the Potential Benefits in the Surface Jet Pump Case Study. Procedia CIRP, 60. https://doi.org/10.1016/j.procir.2017.0 1.026

[40] Miranda De Souza, V., \& Borsato, M. (2016). Combining Stage-Gate ${ }^{\mathrm{TM}}$ model using Set-Based concurrent engineering and sustainable end-of-life principles in a product development assessment tool. Journal of Cleaner Production, 112. https://doi.org/10.1016/j.jclepro.2015.0 6.013

[41] Moreno-Grandas, D. P., HernándezLuna, A. A., \& Wood, K. L. (2010). Integrating preference and possibility to manage uncertainty in lean design. IIE Annual Conference and Expo 2010 Proceedings.

[42] Morgan, J. M., \& Liker, J. K. (2006). The Toyota Product Development System: Integrating People, Process, and Technology. Productivity Press.

[43] Nahm, Y. E., \& Ishikawa, H. (2006). A new 3D-CAD system for set-based parametric design. International Journal of Advanced Manufacturing Technology, 29(1-2). https://doi.org/10.1007/s00170-0042213-5

[44] Nepal, B. P., Yadav, O. P., \& Solanki, R. (2011). Improving the npd process by applying lean principles: A case study. EMJ - Engineering 
Management Journal, 23(3). https://doi.org/10.1080/10429247.2011 .11431910

[45] O'Connor, P. D. T. (1991). Total Design: Integrated Methods for Successful Product Engineering, S. Pugh, Addison-Wesley, 1990. Number of pages: 278, Price: £14.95. Quality and Reliability Engineering International, $7(2)$. https://doi.org/10.1002/qre.468007021 0

[46] Qureshi, A. J., Dantan, J. Y., Bruyere, J., \& Bigot, R. (2011). Set based robust design of systems-application to flange coupling. Global Product Development - Proceedings of the 20th CIRP Design Conference. https://doi.org/10.1007/978-3-64215973-2_34

[47] Radeka, K. (2013). The mastery of innovation: a field guide to lean product development. CRC Press, Taylor \& Francis Group.

[48] Rapp, S., Chinnam, R., Doerry, N., Murat, A., \& Witus, G. (2018). Product development resilience through set-based design. Systems Engineering, 21(5). https://doi.org/10.1002/sys.21449

[49] Raudberget, D. (2010). Practical applications of set-based concurrent engineering in industry. Strojniski Vestnik/Journal of Mechanical Engineering, 56(11). https://doi.org/10.5545/149_DOI_not_ assigned

[50] Rempling, R., Mathern, A., Tarazona Ramos, D., \& Luis Fernández, S. (2019). Automatic structural design by a set-based parametric design method. Automation in Construction, 108. https://doi.org/10.1016/j.autcon.2019.1 02936

[51] Riaz, A., Guenov, M. D., \& MolinaCristobal, A. (2017). Set-based approach to passenger aircraft family design. Journal of Aircraft, 54(1). https://doi.org/10.2514/1.C033747

[52] Saad, D., Rotzer, S., \& Zimmermann, M. (2019). Set-based Design in Agile
Development: Developing a Banana Sorting Module - A Practical Approach. IEEE International Conference on Industrial Engineering and Engineering Management. https://doi.org/10.1109/IEEM44572.20 19.8978748

[53] Schjøtt-Pedersen, N., Welo, T., Ringen, G., \& Raknes, C. A. (2019). Using set-based design for developing a 3D metal forming process. Procedia CIRP, 84. https://doi.org/10.1016/j.procir.2019.0 4.341

[54] Schuh, G., \& Drescher, T. (2014). Systematic leverage of technological assets: A case study for automated tissue engineering. Journal of Engineering and Technology Management - JET-M, 32. https://doi.org/10.1016/j.jengtecman.2 013.10 .001

[55] Serugga, J., Kagioglou, M., \& Tzortzopolous, P. (2020). A utilitarian decision-making approach for front end design-a systematic literature review. In Buildings (Vol. 10, Issue 2). https://doi.org/10.3390/buildings10020 034

[56] Shallcross, N., Parnell, G. S., Pohl, E., \& Specking, E. (2020). Set-based design: The state-of-practice and research opportunities. In Systems Engineering (Vol. 23, Issue 5). https://doi.org/10.1002/sys.21549

[57] Small, C., Parnell, G. S., Pohl, E., Goerger, S. R., Cilli, M., \& Specking, E. (2020). Demonstrating set-based design techniques: an unmanned aerial vehicle case study. Journal of Defense Modeling and Simulation, 17(4). https://doi.org/10.1177/154851291987 2822

[58] Sobek, D., Ward, A., \& Liker, J. (1999). Toyota's Principles of SetBased Concurrent Engineering. Sloan Management Review, 40(2).

[59] Specking, E., Shallcross, N., Parnell, G. S., \& Pohl, E. (2021). Quantitative set-based design to inform design teams. Applied Sciences (Switzerland), 
11(3).

https://doi.org/10.3390/app11031239

[60] Suwanda, S., Al-Ashaab, A., \& Beg, N. (2020). The development of knowledge-shelf to enable an effective set-based concurrent engineering application. International Journal of Internet Manufacturing and Services, 7(4).

https://doi.org/10.1504/IJIMS.2020.11 0256

[61] Telerman, V., Preis, S., Snytnikov, N., \& Ushakov, D. (2006). Interval/set based collaborative engineering design. International Journal of Product Lifecycle Management, 1(2). https://doi.org/10.1504/IJPLM.2006.00 8675

[62] Toche, B., Pellerin, R., \& Fortin, C. (2020). Set-based design: A review and new directions. In Design Science. https://doi.org/10.1017/dsj.2020.16

[63] Trueworthy, A., \& Dupont, B. (2020). The wave energy converter design process: Methods applied in industry and shortcomings of current practices. In Journal of Marine Science and Engineering (Vol. 8, Issue 11). https://doi.org/10.3390/jmse8110932

[64] Wade, Z., Parnell, G. S., Goerger, S., Pohl, E., \& Specking, E. (2019). Convergent set-based design for complex resilient systems. Environment Systems and Decisions, 39(2). https://doi.org/10.1007/s10669019-09731-5

[65] Wang, L., Ming, X. G., Kong, F. B., Li, D., \& Wang, P. P. (2011). Focus on implementation: A framework for lean product development. Journal of Manufacturing Technology Management, 23(1). https://doi.org/10.1108/174103812111 96267

[66] Ward, A., Liker, J. K., Cristiano, J. J., \& Sobek, D. K. (1995). The second Toyota paradox: How delaying decisions can make better cars faster. Sloan Management Review, 36(3), 43.

[67] Ward, A., \& Sobek, D. K. (2014). Lean product and process development (2nd ed.). Lean Enterprise Institute, Inc.

[68] Womack, J. P., Jones, D. T., \& Roos, D. (1990). The machine that changed the world. Rawson Associates.

[69] Yi, Y., Li, W., Xiao, M., \& Gao, L. (2019). A set strategy approach for multidisciplinary robust design optimization under interval uncertainty. Advances in Mechanical Engineering, 11(1). https://doi.org/10.1177/168781401882 0383

\section{Creative Commons Attribution License 4.0 (Attribution 4.0 International, CC BY 4.0)}

This article is published under the terms of the Creative Commons Attribution License 4.0 https://creativecommons.org/licenses/by/4.0/deed.en US 